\title{
The role of supplemental oxygen during submaximal exercise in patients with cystic fibrosis
}

\author{
E.F. McKone, S.C. Barry, M.X. FitzGerald, C.G. Gallagher
}

\begin{abstract}
The role of supplemental oxygen during submaximal exercise in patients with cystic fibrosis. E.F. McKone, S.C. Barry, M.X. FitzGerald, C.G. Gallagher. (C) ERS Journals Ltd 2002

ABSTRACT: Repeated bouts of submaximal exercise are an important part of most pulmonary rehabilitation programmes. Patients with moderate-to-severe cystic fibrosis (CF) often demonstrate oxygen desaturation during submaximal exercise, which may limit their ability to participate in these programmes. This study examines whether arterial desaturation contributes to submaximal exercise limitation by testing whether supplemental $\mathrm{O}_{2}$ improves submaximal exercise capacity.

Eight patients with CF (mean forced expiratory volume in one second $41 \%$ predicted) each underwent two submaximal exercise tests on a bicycle ergometer at $80 \%$ of maximal workload. The two tests were identical except for the addition of supplemental $\mathrm{O}_{2}$ (inspiratory $\mathrm{O}_{2}$ fraction $39 \%$ ) during one of the tests.

Exercise duration was significantly longer in the supplemental $\mathrm{O}_{2}$ study versus control $(673 \pm 63 \mathrm{~s}$ versus $835 \pm 99 \mathrm{~s})$. Arterial $\mathrm{O}_{2}$ saturation was also higher in the supplemental $\mathrm{O}_{2}$ study than the control exercise test $(96 \pm 0.3 \%$ versus $86 \pm 1.5 \%)$. There was no statistical difference at end exercise between $\mathrm{O}_{2}$ consumption, minute ventilation and heart rate. There was a significant relationship between improvement in exercise capacity and the amount of desaturation during the control exercise test.

Results indicate that supplemental oxygen improves submaximal exercise capacity in patients with moderate-to-severe cystic fibrosis. Oxygen therapy may be an important intervention to improve participation and maximise the benefits of pulmonary exercise rehabilitation programmes.
\end{abstract}

Eur Respir J 2002; 20: 134-142.
Dept of Respiratory Medicine and National Referral Centre for Adult Cystic Fibrosis, St Vincent's University Hospital, Dublin 4, Ireland.

\section{Correspondence: C.G. Gallagher \\ Dept of Respiratory Medicine \\ St Vincent's University Hospital Dublin 4 \\ Republic of Ireland \\ Fax: 35312094989 \\ E-mail: v.hearn@st-vincent.ie}

Keywords: Cystic fibrosis

oxygen

submaximal exercise

Received: April 112001

Accepted after revision: February 25 2002

This study was supported by the Health Research Board and the Cystic Fibrosis Research Trust. E.F. McKone is supported by a research fellowship from the Irish Lung Association.
Pulmonary rehabilitation programmes have become an important tool in the management of patients with advanced respiratory disease. Regular exercise is an important part of these programmes and has been shown to have significant benefits for respiratory patients, including improved quality of life and increased cardiovascular fitness [1-3]. Although the majority of studies looking at the benefits of pulmonary rehabilitation have examined the effects on patients with chronic obstructive lung disease (COPD), there is evidence that regular exercise has significant beneficial effects for patients with many different respiratory disorders.

Patients with cystic fibrosis $(\mathrm{CF})$ often have reduced maximal exercise performance [4-8], which is associated with poor prognosis $[9,10]$ and impaired quality of life $[11,12]$. In recent years, the role of regular exercise in the management of patients with $\mathrm{CF}$ has been examined $[13,14]$. These studies have demonstrated that many exercise programmes have significant benefits for $\mathrm{CF}$ patients, including increased cardiovascular fitness and enhanced quality of life.

Unfortunately, some patients with $\mathrm{CF}$ are unable to participate in exercise programmes due to severe exercise limitation. This is particularly true for sustained high-intensity exercise, which may be associated with the greatest physiological benefits $[1,15,16]$. Studies examining factors that may limit maximal exercise performance in $\mathrm{CF}$ patients have suggested that abnormalities of respiratory function, including abnormal pulmonary mechanics and gas exchange, as well as poor nutrition and peripheral muscle dysfunction, may be contributors [17-20]. Despite the extensive knowledge of factors limiting maximal exercise performance in patients with $\mathrm{CF}$, very little attention has been paid to factors that limit submaximal exercise capacity. As submaximal exercise is more relevant to daily activities and is an intricate part of most exercise rehabilitation programmes, understanding factors that limit submaximal exercise is an important goal in order to develop therapies that might improve performance.

The present authors hypothesised that submaximal exercise performance is limited by arterial hypoxaemia. This hypothesis was based on the observation that patients with moderate-to-severe $\mathrm{CF}$ often demonstrate arterial desaturation during exercise. If arterial desaturation limits submaximal exercise performance, then supplemental oxygen should improve submaximal exercise capacity. Studies that have examined the role of supplemental $\mathrm{O}_{2}$ during maximal 
exercise have shown some improvement in exercise capacity [21], although findings have been conflicting $[18,22]$. Supplemental $\mathrm{O}_{2}$ has also been examined during submaximal exercise [22-24]. However, it has only been used to prevent $\mathrm{O}_{2}$ desaturation and it is not known whether supplemental $\mathrm{O}_{2}$ improves submaximal exercise capacity. An improvement in submaximal exercise capacity would be clinically important as it could be applied to patients with $\mathrm{CF}$ who otherwise may not be considered suitable for exercise rehabilitation programmes because of severe exercise limitation. To test this, the effects of supplemental $\mathrm{O}_{2}$ on submaximal exercise capacity in a $\mathrm{CF}$ patient population were examined.

\section{Methods}

\section{Patients selection}

Subjects (seven males and one female) were recruited from outpatients of the National Adult Cystic Fibrosis Unit, St Vincent's University Hospital, Dublin, Ireland. All subjects had clinical, radiological and physiological evidence of CF lung disease and had been diagnosed as having $\mathrm{CF}$ based on clinical features, abnormal sweat test (sweat sodium/ chloride $>60 \mathrm{mmol} \cdot \mathrm{L}^{-1}$ ) and genotyping. All subjects were assessed by a physician prior to inclusion and were clinically stable. Patients had no evidence of rheumatological, neuromuscular, cardiac, peripheral vascular, or any disease apart from CF that might impair exercise tolerance.

Pulmonary function testing was carried out on each patient before and after exercise testing. Forced expiratory volume in one second (FEV1) and forced vital capacity (FVC) were measured using recommended techniques, and predicted normal values [25] were used to calculate percentage predicted values.

The study was approved by the Ethics Committee of St Vincent's University Hospital. All subjects gave informed consent to the procedures.

\section{Exercise protocol}

Before each exercise study, FEV1 and FVC were measured with a spirometer (Pneumocheck-Welch Allyn, Skaneateles Falls, NY, USA). At least three well-coordinated maximal efforts were obtained and the highest value obtained for each variable was recorded. The subjects each underwent three exercise tests over a 14-day period with each test separated by $\geqslant 48 \mathrm{~h}$. The exercise tests consisted of a maximal test followed by two submaximal exercise tests at $80 \%$ of the peak workload reached during the maximal test. Exercise was performed at the same time of day on each occasion. The subjects were asked to avoid strenuous activity for $\geqslant 24 \mathrm{~h}$ prior to exercise testing as well as food or caffeinated drinks in the preceding $2 \mathrm{~h}$. All patients were instructed to take all of their maintenance medications as usual prior to testing. All testing was performed on an electrically-braked cycle ergometer (Excalibur; Lode BV, Groningen, the Netherlands).

For the maximal exercise test, after mounting the cycle ergometer, each patient put on a noseclip, inserted the mouthpiece attached to a Hans Rudolph valve (Kansas City, MO, USA) and breathed room air comfortably for $\geqslant 2 \mathrm{~min}$. Baseline measurements were then taken over $2 \mathrm{~min}$. The initial exercise workload was $15 \mathrm{~W}$ and was increased by $15 \mathrm{~W} \cdot \mathrm{min}^{-1}$ in a ramp fashion until exhaustion. With the use of speedometer feedback, each subject chose the pedalling rate within a range of 50-70 rpm. All subjects were instructed in an identical manner by the same operator for all exercise studies. The subjects were told that they should continue to exercise until they could exercise no more. No other type of encouragement was offered and no communication was made with the subjects during the testing to ensure consistency of the protocol.

For the two submaximal studies, the initial warm up work rate was $15 \mathrm{~W} \cdot \mathrm{min}^{-1}$ for $2 \mathrm{~min}$ followed by an immediate rise to $80 \%$ of the peak workload reached in the maximal test. The control study was carried out while breathing room air and the $\mathrm{O}_{2}$ study was carried out while breathing $39 \% \mathrm{O}_{2}\left(\mathrm{O}_{2} 39 \%\right.$, balance (BAL) nitrogen $\left(\mathrm{N}_{2}\right)$; BOC Gases, Dublin, Ireland). The control and $\mathrm{O}_{2}$ exercise tests were otherwise identical. The order of testing for control and $\mathrm{O}_{2}$ was randomised for each patient to minimise any possible training or learning effect.

Electrocardiographic leads attached to the chest enabled continuous monitoring of the heart rate (HR) and electrocardiogram. Arterial oxygen saturation $\left(\mathrm{Sa}, \mathrm{O}_{2}\right)$ was monitored by pulse oximetry (SAT-TRAK Pulse oximeter; Sensor Medics, Yorba Linda, CA, USA). The non-rebreathing valve was connected via wide bore tubing to a $2.6 \mathrm{~L}$ mixing chamber with a heated wire-flow sensor at the entrance to the mixing chamber (Mass Flow Sensor ${ }^{(i m}$; Sensor Medics). Respired gases were sampled by rapidly responding $\mathrm{O}_{2}$ (paramagnetic) and carbon dioxide (infrared) analysers. Respiratory and ventilatory data were averaged over a 20 -s time period to give measured variables. All equipment was calibrated before each exercise study using calibration syringes and precision $\mathrm{O}_{2}$ and carbon dioxide gas mixtures. All signals were displayed on a computer screen in real time during the exercise test. Data was also stored on computer hard disk for later analysis.

\section{Inhaled gas}

As $\mathrm{O}_{2}$ consumption $\left(V^{\prime} \mathrm{O}_{2}\right)$ was measured during the exercise tests, a number of precautions were taken to ensure that the respired gas measurements were accurate during the tests with supplemental $\mathrm{O}_{2}$. Prior to exercise with supplemental $\mathrm{O}_{2}$, the equipment was calibrated to ensure accurate measurement of the inspired gas concentrations $\left(\mathrm{O}_{2}=39\right.$, BAL $\mathrm{N}_{2}$; BOC Gases). Each subject put on a noseclip and breathed through a Hans Rudolph Valve with the inspired limb connected to a 1,000 L Douglas Bag partially filled with the humidified $\mathrm{O}_{2}$. The patients then rested, comfortably breathing for $\geqslant 6 \mathrm{~min}$ to ensure that their 
lungs were completely empty of room air. The $V^{\prime} \mathrm{O}_{2}$ was measured using the mixing chamber method because of problems measuring $V^{\prime} \mathrm{O}_{2}$ when the Douglas bag method is used during hyperoxic breathing [26]. Baseline measurements were recorded until there was $<10 \%$ variability between repeated measurements of $V^{\prime} \mathrm{O}_{2}$ over a $2 \mathrm{~min}$ period (i.e. steady state $V^{\prime} \mathrm{O}_{2}$ was reached). Inspiratory oxygen fraction $\left(F I, \mathrm{O}_{2}\right)$ was measured every minute during exercise through a sampling port in the Douglas Bag.

Patients in each study were blinded to the content of the inhaled gas and, to ensure consistency of the protocol, room air was humidified and administered during the control study in an identical way to the supplemental $\mathrm{O}_{2}$ in the supplemental $\mathrm{O}_{2}$ study. The primary investigator was not blinded to the content of the inhaled gas during each exercise test.

\section{Data analysis}

Minute ventilation $\left(V^{\prime} \mathrm{E}\right)$, tidal volume $(V \mathrm{~T})$, respiratory frequency $(f \mathrm{R}), \mathrm{HR}, V^{\prime} \mathrm{O}_{2}$ and carbon dioxide production $\left(V^{\prime} \mathrm{CO}_{2}\right)$ were measured every $20 \mathrm{~s}$ using standard formula [27, 28]. End-tidal $\mathrm{CO}_{2}$ tension $\left(P\right.$ ET, $\left.\mathrm{CO}_{2}\right)$ was measured every minute through a sampling port at the patient's mouth. $V^{\prime} \mathrm{E}$ and $V \mathrm{~T}$ were expressed at body temperature pressure and saturation, and $V^{\prime} \mathrm{O}_{2}$ and $V^{\prime} \mathrm{CO}_{2}$ were expressed at standard temperature pressure and dry. Predicted peak $V^{\prime} \mathrm{O}_{2}$ during exercise was calculated as [28]:

$$
\begin{aligned}
\text { Peak } V_{\mathrm{O}_{2}}^{\prime}= & 0.83 \mathrm{ht}^{2.7} \times(1-0.007 \text { age }(\mathrm{yrs})) \\
& \times(1-0.25 \mathrm{~S})
\end{aligned}
$$

where height (ht) is in meters and $\mathrm{S}$ is a factor taking account of sex ( 0 males and 1 female). Predicted peak HR was calculated as [27]:

$$
\text { Peak HR }=210-0.66 \text { age }(\text { yrs })
$$

Maximum voluntary ventilation (MVV) was predicted using the equation [29]:

$$
\mathrm{FEV}_{1} \times 35
$$

The magnitude of dyspnoea was assessed using the Borg Scale [30] in response to the question "How breathless do you feel?", with the subject pointing to the appropriate number on the scale. Leg discomfort was assessed using the Borg Scale as above, in response to the question "How much leg discomfort do you feel?" Each patient was also asked their reason for stopping exercise immediately after each exercise test.

\section{Statistical analysis}

Data collected at rest, end exercise and at matched exercise times were used in the analysis.

The statistical significance of group mean data at end exercise from the two experimental days was determined by paired t-testing. Data at matched exercise times were compared using analysis of variance (ANOVA) for repeated measures [31].
Analysis of the Borg Scale was performed using Wilcoxon's signed rank test. The relationship between the improvement in exercise duration with $\mathrm{O}_{2}$ and the drop in $\mathrm{O}_{2}$ saturation during the control study, FEV1 (\% pred), body mass index, $\mathrm{Sa}_{\mathrm{a}} \mathrm{O}_{2}$ at rest and rate of change of $V^{\prime} E$ during exercise, was analysed by linear regression. A p-value of $<0.05$ was considered significant. The results are expressed as mean \pm SEM.

\section{Results}

Characteristics of the study population at rest and the end of maximal exercise are shown in table 1. Subjects completed all three exercise tests without any complications and no exercise tests were terminated by the physician.

Analysis the of group mean data collected before exercise showed no significant difference in baseline spirometric values, $\mathrm{Sa}_{\mathrm{a}} \mathrm{O}_{2}$ or $\mathrm{HR}$ between the two studies. Mean FEV1 was $41 \%$ predicted (range $20-61 \%$ ). Mean FVC was $63 \%$ pred (range $30-83 \%$ ). All patients showed a reduced maximal exercise tolerance with a mean maximal $V^{\prime} \mathrm{O}_{2}$ of $53 \%$ pred (range $35-69 \%$ ). Mean maximal HR was $91 \%$ pred (range $85-102 \%$ ) at the end of the maximal exercise test.

Table 2 shows the group mean \pm SEM for control and supplemental $\mathrm{O}_{2}$ studies collected at the end of submaximal exercise.

Exercise duration was significantly different between supplemental $\mathrm{O}_{2}$ and control studies $(835 \pm 99 \mathrm{~s}$ versus $673 \pm 63 \mathrm{~s}, \mathrm{p}<0.05)$. Group mean and individual exercise duration are shown in figure 1. Borg scale dyspnoea was the same at end exercise in the two submaximal studies. $\mathrm{Sa}_{\mathrm{a}} \mathrm{O}_{2}$ was significantly higher at end exercise in the supplemental $\mathrm{O}_{2}$ study versus the control study $(96 \pm 0.3 \%$ versus $86 \pm 1.5 \%, \mathrm{p}<0.001)$. Figure 2 shows group mean and individual results for Borg scale dyspnoea and $\mathrm{Sa}_{\mathrm{a}} \mathrm{O}_{2}$ at end exercise. There was no significant difference between Borg scale leg discomfort in the two submaximal studies.

There was no significant difference in $V^{\prime} \mathrm{O}_{2}, V^{\prime} \mathrm{CO}_{2}$, $V^{\prime} \mathrm{E}, V \mathrm{~T}, f \mathrm{R}$ and $\mathrm{HR}$ between the two tests during exercise or at end exercise. Figure 3 shows group mean \pm SEM for $V^{\prime} \mathrm{O}_{2}$ and $\mathrm{HR}$ at end exercise and at matched exercise times. There was no difference in $V^{\prime} \mathrm{O}_{2}$ and HR between the two studies during exercise.

Figure 4 shows group mean \pm SEM for $V^{\prime} \mathrm{E}, V \mathrm{~T}$ and $f \mathrm{R}$ at end exercise and at matched times during exercise. There was a trend for lower ventilation during exercise, largely as a result of a drop in $f \mathrm{R}$ but this was not statistically significant.

Figure 5 shows $S \mathrm{a}, \mathrm{O}_{2}$ and $P \mathrm{ET}, \mathrm{CO}_{2}$ for the control study and the supplemental $\mathrm{O}_{2}$ study during exercise. There was a significant difference in $\mathrm{O}_{2}$ saturation between the control study and $\mathrm{O}_{2}$ study at all stages of the exercise. $P$ ET, $\mathrm{CO}_{2}$ was significantly higher at end exercise in the supplemental $\mathrm{O}_{2}$ study than in the control study.

Figure 6 shows a Hey plot composite pattern of breathing for all subjects during control and supplemental $\mathrm{O}_{2}$ studies. The initial increase in $V^{\prime} \mathrm{E}$ was primarily due to increases in $f \mathrm{R}$ and $V \mathrm{~T}$, whereas, later 
Table 1. - Characteristics of the study population

\begin{tabular}{lc}
\hline Subject $\mathrm{n}$ & 8 \\
Age yrs & $26 \pm 1$ \\
Sex M:F & $7: 1$ \\
FEV1 L & $1.67 \pm 0.23$ \\
FEV1 \% pred & 41 \\
FVC L & $2.99 \pm 0.32$ \\
FVC \% pred & 63 \\
FEV $1 / \mathrm{FVC} \%$ & $56 \pm 5$ \\
Maximum voluntary & $59 \pm 8$ \\
$\quad$ ventilation $\mathrm{L} \cdot \mathrm{min}^{-1}$ & \\
Maximum $V^{\prime} \mathrm{O}_{2} \mathrm{~L} \cdot \mathrm{min}^{-1}$ & $1.50 \pm 0.14$ \\
Maximum $V^{\prime} \mathrm{O}_{2} \% \mathrm{pred}^{-1}$ & 53 \\
Maximum $V^{\prime} \mathrm{O}_{2} \mathrm{~mL} \cdot \mathrm{kg}^{-1} \cdot \mathrm{min}^{-1}$ & $25.9 \pm 2.35$ \\
Maximum $V^{\prime} \mathrm{E} \mathrm{L} \cdot \mathrm{min}^{-1}$ & $59 \pm 6$ \\
$V^{\prime} \mathrm{E} / \mathrm{MVV} \%$ & $100 \pm 12$ \\
Maximum heart rate beats $\cdot \mathrm{min}^{-1}$ & $176 \pm 3$ \\
Maximum heart rate \% pred & $91 \pm 2$ \\
BMI kg $\cdot \mathrm{m}^{-2}$ & $19.9 \pm 0.7$ \\
Sa, $\mathrm{O}_{2} \%$ & $86 \pm 2$ \\
\hline
\end{tabular}

Data are presented as mean \pm SEM unless otherwise stated; M: male; F: female; FEV1: forced expiratory volume in one second; FVC: forced vital capacity; MVV: maximum voluntary ventilation $(\mathrm{FEV} 1 \times 35)$; maximum $V^{\prime} \mathrm{O}_{2}$ : oxygen consumption at end of maximal exercise test; maximum $V^{\prime} \mathrm{E}$ : ventilation at end of maximal exercise test; maximum heart rate: heart rate at end of maximal exercise test; BMI: body mass index; $\mathrm{Sa}_{\mathrm{a}, \mathrm{O}_{2}}$ : arterial oxygen saturation at end of maximal exercise test.

Table 2. - Values obtained at end of submaximal exercise $(n=8)$

\begin{tabular}{|c|c|c|c|}
\hline Values & Control & $\mathrm{O}_{2}$ & p-value \\
\hline Workload W & $101 \pm 10$ & $101 \pm 10$ & NS \\
\hline Exercise duration $\mathrm{s}$ & $673 \pm 63$ & $835 \pm 99$ & $\mathrm{p}<0.05$ \\
\hline$V^{\prime} \mathrm{O}_{2} \mathrm{~L} \cdot \mathrm{min}^{-1}$ & $1.59 \pm 0.13$ & $1.65 \pm 0.15$ & NS \\
\hline$V^{\prime} \mathrm{O}_{2} \mathrm{~mL} \cdot \mathrm{kg}^{-1} \cdot \mathrm{min}^{-1}$ & $27.8 \pm 2.3$ & $28.6 \pm 2.8$ & NS \\
\hline$V^{\prime} \mathrm{CO}_{2} \mathrm{~L} \cdot \mathrm{min}^{-1}$ & $1.73 \pm 0.14$ & $1.73 \pm 0.15$ & NS \\
\hline $\mathrm{R}$ & $1.08 \pm 0.03$ & $1.05 \pm 0.03$ & NS \\
\hline$P$ ET, $\mathrm{CO}_{2} \mathrm{mmHg}$ & $41 \pm 3$ & $43 \pm 4$ & $\mathrm{p}<0.05$ \\
\hline$V^{\prime} \mathrm{E} \mathrm{L} \cdot \mathrm{min}^{-1}$ & $59 \pm 6$ & $58 \pm 6$ & NS \\
\hline$V^{\prime} \mathrm{E} / \mathrm{MVV} \%$ & $106 \pm 6$ & $103 \pm 6$ & NS \\
\hline$f \mathrm{R} \min ^{-1}$ & $37 \pm 2$ & $38 \pm 3$ & NS \\
\hline$V \mathrm{~T} \mathrm{~L}$ & $1.56 \pm 0.17$ & $1.55 \pm 0.17$ & NS \\
\hline HR bpm & $178 \pm 3$ & $171 \pm 4$ & NS \\
\hline HR \% pred & $90 \pm 1$ & $89 \pm 2$ & NS \\
\hline Borg-dyspnoea & $4 \pm 1$ & $4 \pm 1$ & NS \\
\hline $\mathrm{Sa}_{\mathrm{a}, \mathrm{O}_{2}} \%$ & $86 \pm 2$ & $96 \pm 1$ & $\mathrm{p}<0.001$ \\
\hline
\end{tabular}

Data are presented as mean \pm SEM unless otherwise stated; $\mathrm{O}_{2}$ : oxygen; $V^{\prime} \mathrm{O}_{2}: \mathrm{O}_{2}$ consumption; $V^{\prime} \mathrm{CO}_{2}$ : carbon dioxide production; R: respiratory quotient; $P \mathrm{ET}, \mathrm{CO}_{2}$ : end-tidal carbon dioxide tension; $V^{\prime} \mathrm{E}$ : minute ventilation; MVV: maximum voluntary ventilation; $f \mathrm{R}$ : respiratory frequency; $V \mathrm{~T}$ : tidal volume; HR: heart rate; $\mathrm{Sa}_{\mathrm{a}} \mathrm{O}_{2}$ : arterial oxygen saturation.

in exercise, the increase in $V^{\prime} \mathrm{E}$ was mainly due to increases in $f \mathrm{R}$ as $V \mathrm{~T}$ reached a plateau. Breathing pattern was similar during both studies. Table 3 shows $V \mathrm{~T}$ and $f \mathrm{R}$ at $30 \%, 50 \%$ and $75 \%$ peak $V^{\prime} \mathrm{E}$ reached during control study. There was no significant difference between $V \mathrm{~T}$ and $f \mathrm{R}$ at matched levels of ventilation during exercise. The ratio of peak $V^{\prime} \mathrm{E}$ to

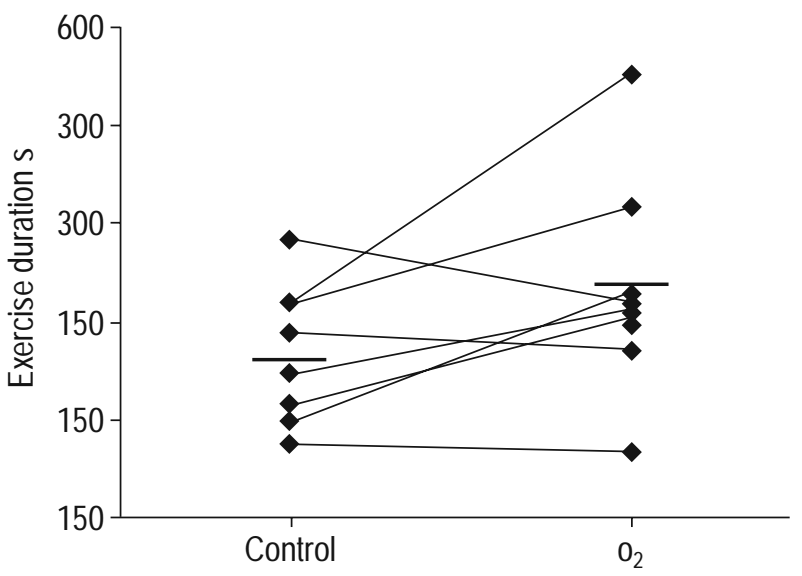

Fig. 1. - Group mean $(-)$ and individual data $(n=8)$ for submaximal exercise duration in control and supplemental oxygen $\left(\mathrm{O}_{2}\right)$ studies. $\mathrm{p}<0.05$.
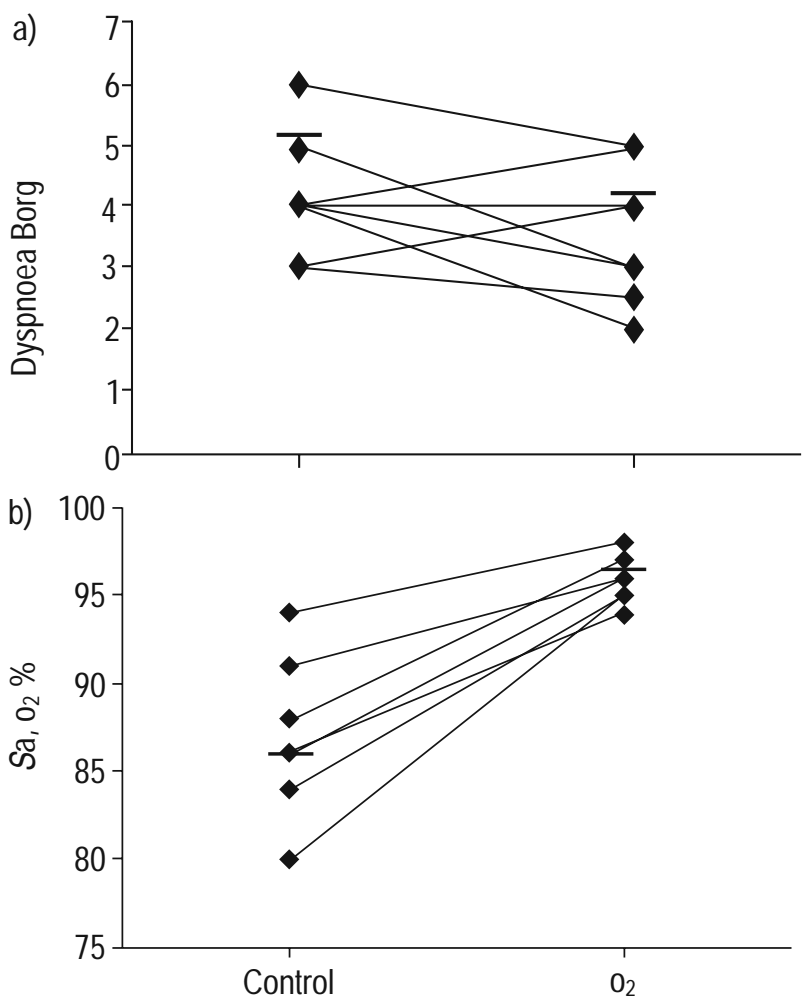

Fig. 2. - Group mean $(-)$ and individual data $(\mathrm{n}=8)$ for a) Borg dyspnoea ( $\mathrm{p}=\mathrm{NS})$ and $\mathrm{b})$ arterial oxygen saturation $\left(\mathrm{Sa}_{\mathrm{a}, \mathrm{O}}\right.$, $\mathrm{p}<0.001)$ at end exercise duration in control and supplemental oxygen $\left(\mathrm{O}_{2}\right)$ studies.

MVV was $106 \%$ at end exercise in the control study and $103 \%$ at end exercise in the supplemental $\mathrm{O}_{2}$ study.

Linear regression was used to predict patients who would benefit from the use of supplemental $\mathrm{O}_{2}$ during submaximal exercise. It was found that the drop in $\mathrm{O}_{2}$ saturation seen during the control submaximal exercise study was the only predictor of change in exercise duration with supplemental $\mathrm{O}_{2}$ 

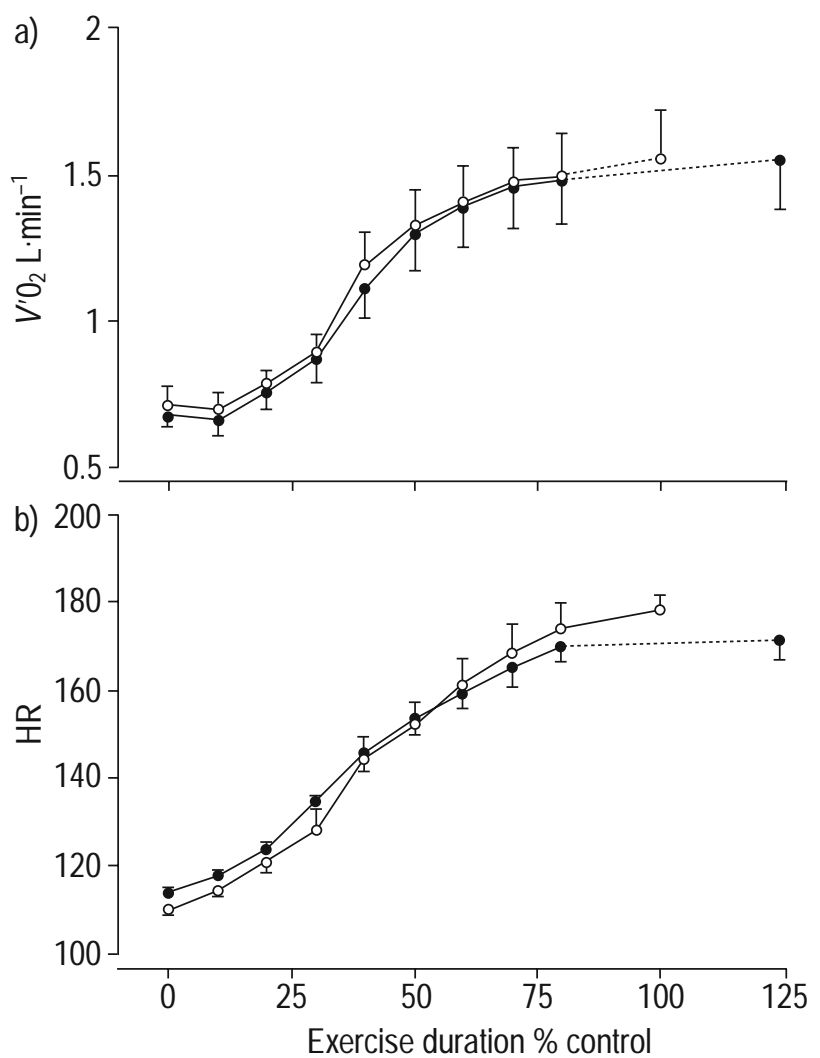

Fig. 3.-Group mean (SEM) values for a) oxygen consumption $\left(V^{\prime} \mathrm{O}_{2}\right)$ and b) heart rate $(\mathrm{HR})$ at end exercise and at matched times during exercise $(n=8)$. $\bigcirc$ : control; O: $39 \% \mathrm{O}_{2} ;-\cdots$ - join values from last common exercise time to that at end exercise.

$\left(r^{2}=0.45, p=0.04\right)$, as can be seen in Figure 7. There was no relationship between improvement in submaximal exercise duration on $\mathrm{O}_{2}$ and $\mathrm{FEV} 1$ ( $\%$ pred), body mass index, resting room air $\mathrm{O}_{2}$ saturation, end-exercise room air $\mathrm{O}_{2}$ saturation or change in $V^{\prime} \mathrm{E}$ with $\mathrm{O}_{2}$.

\section{Discussion}

The main findings in this study are that: 1) submaximal exercise capacity in patients with moderateto-severe $\mathrm{CF}$ is likely to be partly limited by arterial hypoxaemia and that supplemental $\mathrm{O}_{2}$ during exercise improves submaximal exercise capacity; and 2) the improvement in submaximal exercise capacity may be predicted by the degree of $\mathrm{O}_{2}$ desaturation that occurs during a control submaximal exercise test.

\section{Exercise and cystic fibrosis}

Maximal exercise testing in patients with $\mathrm{CF}$ has become an important tool in assessing disease severity and in predicting overall outcome. Recent studies have shown that reduced maximal exercise capacity in $\mathrm{CF}$ patients is associated with impaired quality of life $[11,12]$ and poor prognosis $[9,10]$. This has lead to the hypothesis that increasing exercise capacity in these patients may result in improved survival.
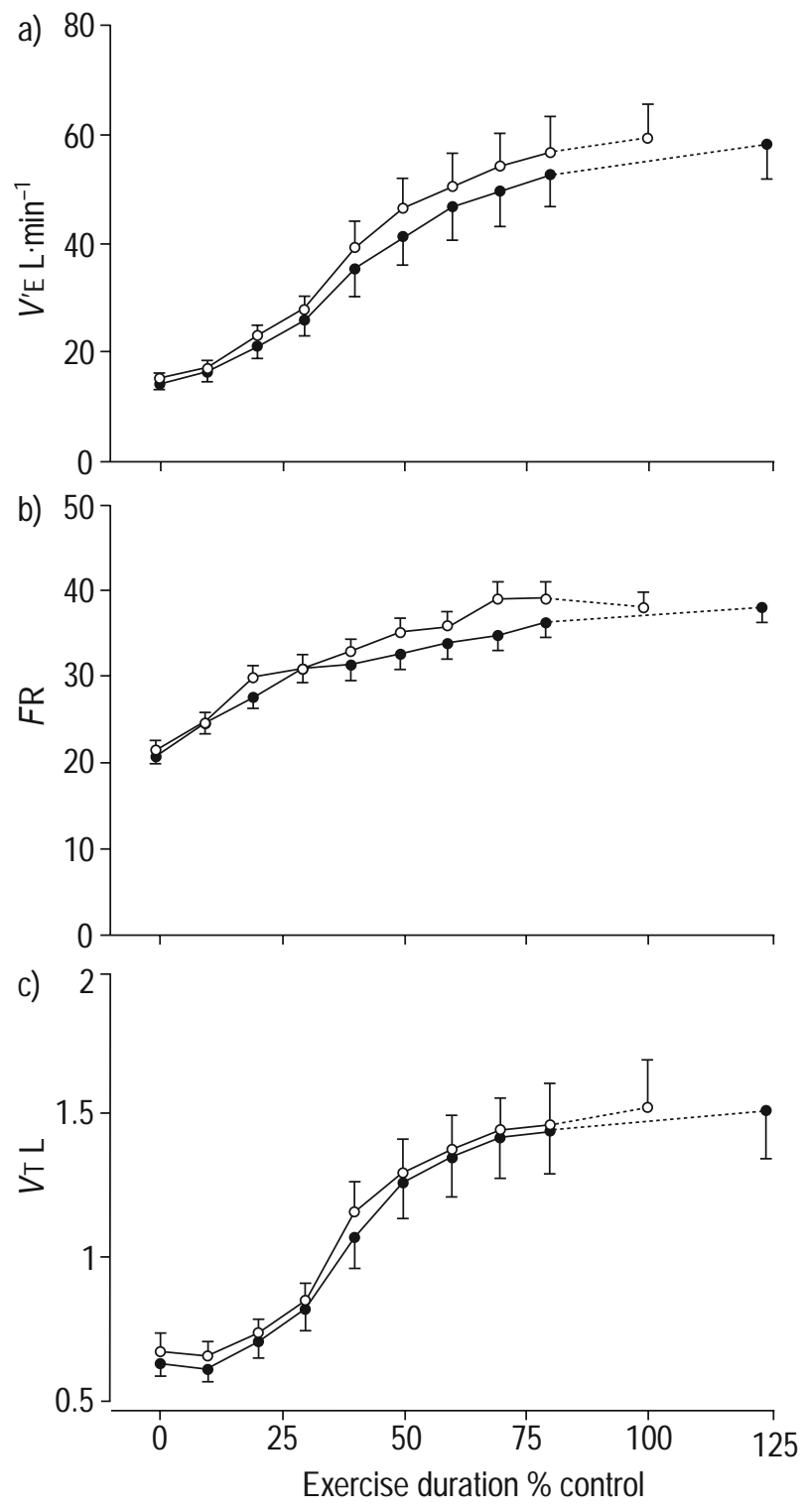

Fig. 4.-Group mean (SEM) values for a) minute ventilation ( $\left.V^{\prime} \mathrm{E}\right)$, b) tidal volume $(V \mathrm{~T})$ and c) respiratory frequency $(f \mathrm{R})$ at end exercise and at matched times during exercise $(n=8)$. $\bigcirc$ : control; : $39 \% \mathrm{O}_{2} ;-\cdots$ - join values from last common exercise time to that at end exercise.

In recent years the role of regular exercise in the management of patients with $\mathrm{CF}$ has been extensively examined. These studies have demonstrated that regular exercise has significant benefits for $\mathrm{CF}$ patients, including increased cardiovascular fitness, improved pulmonary function and exercise capacity and enhanced quality of life. The role of exercise in $\mathrm{CF}$ has been comprehensively reviewed elsewhere $[13,14]$ and is not discussed here.

It is important that exercise programmes for $\mathrm{CF}$ patients are safe and well tolerated. The majority of studies that have shown exercise programs to be of benefit in $\mathrm{CF}$ patients have involved bouts of submaximal exercise repeated at least two to three times a week for an extended period of time. Patients 

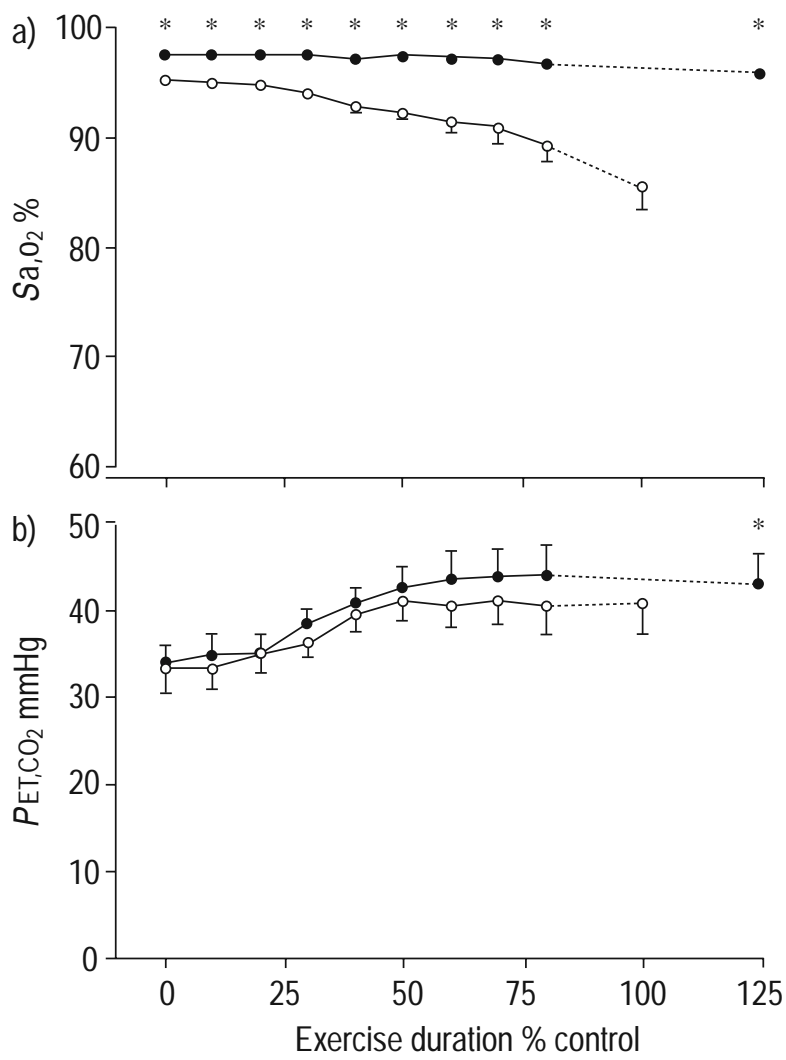

Fig. 5.-Group mean (SEM) values for a) arterial oxygen saturation $\left(S \mathrm{a}, \mathrm{O}_{2}\right)$ and $\left.\mathrm{b}\right)$ end-tidal carbon dioxide tension $\left(\mathrm{PET}, \mathrm{CO}_{2}\right)$ at end exercise and at matched times during exercise $(n=8) . ~ \bigcirc$ : control; : $39 \% \mathrm{O}_{2} ;---$ : join values from last common exercise time to that at end exercise. *: $\mathrm{p}<0.05$.

with moderate-to-severe $\mathrm{CF}$ often do not tolerate submaximal exercise, even at very low workloads, due to severe exercise limitation. As these are the patients with the poorest prognosis and most impaired quality of life, finding ways to improve their ability to

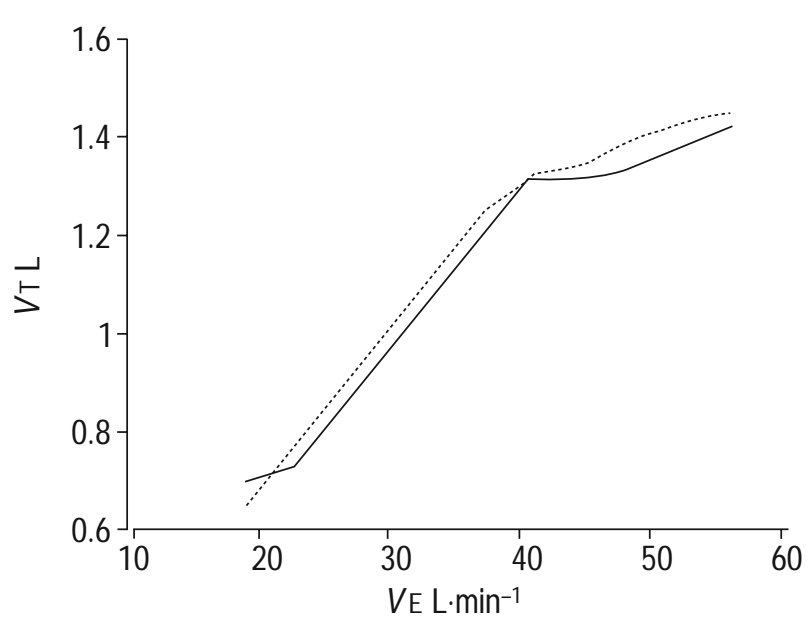

Fig. 6.-Breathing pattern during exercise in control $(-)$ and supplemental oxygen (- - ) studies $(\mathrm{n}=8)$. VT: tidal volume; $V^{\prime} \mathrm{E}$ : minute ventilation.
Table 3.-Breathing pattern at three matched ventilatory levels

\begin{tabular}{lcccc}
\hline$\% V^{\prime}$ E max & Variable & Control & $\mathrm{O}_{2}$ & p-value \\
\hline $30 \%$ & $V^{\prime} \mathrm{E} \mathrm{L} \cdot \mathrm{min}^{-1}$ & $18.6 \pm 1.69$ & $18.6 \pm 1.74$ & \\
& $V \mathrm{~T} \mathrm{~L}$ & $0.69 \pm 0.06$ & $0.66 \pm 0.04$ & $\mathrm{NS}$ \\
$50 \%$ & $f \mathrm{R}$ & $27 \pm 2$ & $28 \pm 2$ & $\mathrm{NS}$ \\
& $V^{\prime} \mathrm{E} \cdot \mathrm{min}^{-1}$ & $29.8 \pm 2.53$ & $29.8 \pm 2.08$ & \\
& $V \mathrm{~T} \mathrm{~L}$ & $0.96 \pm 0.09$ & $1.00 \pm 0.09$ & $\mathrm{NS}$ \\
$75 \%$ & $f \mathrm{R}$ & $31 \pm 2$ & $30 \pm 2$ & $\mathrm{NS}$ \\
& $V^{\prime} \mathrm{E} \cdot \min ^{-1}$ & $44.5 \pm 4.45$ & $44.5 \pm 4.38$ & \\
& $V \mathrm{~T} \mathrm{~L}$ & $1.31 \pm 0.11$ & $1.34 \pm 0.12$ & $\mathrm{NS}$ \\
& $f \mathrm{R}$ & $35 \pm 2$ & $34 \pm 2$ & $\mathrm{NS}$ \\
\hline
\end{tabular}

$V^{\prime}$ E max: maximum ventilation reached in control study; $\mathrm{O}_{2}$ : oxygen; $V^{\prime} \mathrm{E}$ : minute ventilation during exercise; $V$ T: tidal volume; $f \mathrm{R}$ : respiratory frequency; $\mathrm{NS}=\mathrm{p}>0.05$.

participate in exercise rehabilitation programmes is important.

Based on the observation that some CF patients desaturate during exercise, it was hypothesised that submaximal exercise in CF patients is limited by arterial hypoxaemia. To test this hypothesis, patients were exercised at $80 \%$ of maximal workload ( $\mathrm{Wmax}$ ) while breathing either room air or supplemental $\mathrm{O}_{2}$. The $80 \%$ Wmax was chosen because of evidence that repeated bouts of high-level exercise (above the anaerobic threshold) may be associated with the greatest physiological benefit in patients with COPD $[15,16]$. The effects of supplemental $\mathrm{O}_{2}$ have been examined previously during maximal exercise in normal subjects and patients with CF. In normal subjects, supplemental $\mathrm{O}_{2}$ has consistantly been shown to improve maximal exercise capacity [32], while in $\mathrm{CF}$ patients, studies of supplemental $\mathrm{O}_{2}$ during exercise have been conflicting, with one study showing an improvement in exercise capacity [21] and others showing no significant benefit $[18,22]$. The reasons for these conflicting results are unclear and may relate to differences in disease severity between the groups studied, as the CF patients that benefit

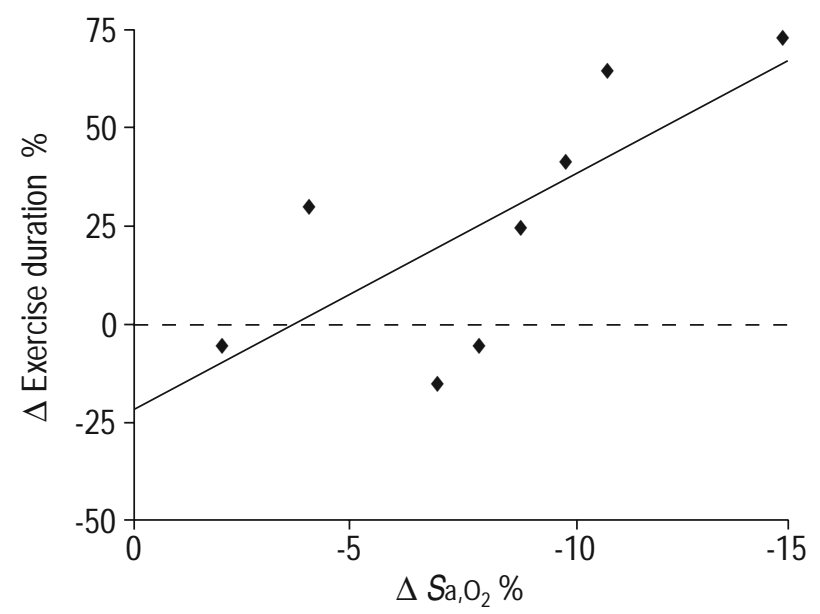

Fig. 7.-Relationship between the improvement in exercise duration on oxygen ( $\Delta$ exercise duration) and the drop in arterial oxygen saturation $\left(\mathrm{S}_{\mathrm{a}}, \mathrm{O}_{2}\right)$ during the control study. $\mathrm{r}^{2}=0.45$. $\mathrm{p}=0.04$. 
from $\mathrm{O}_{2}$ appear to have had more severe disease. $\mathrm{O}_{2}$ supplementation during submaximal exercise has also been examined previously in patients with CF [22-24], but has only been used to prevent potentially dangerous desaturation during exercise, and has never been examined as a possible therapy to improve submaximal exercise capacity or to test whether arterial $\mathrm{O}_{2}$ desaturation limits submaximal exercise capacity. If arterial hypoxaemia is a significant limiting factor during submaximal exercise then preventing it through the use of supplemental $\mathrm{O}_{2}$ should improve exercise capacity. The current authors found that supplemental $\mathrm{O}_{2}$ improved mean submaximal exercise capacity by an average of $26 \%$, suggesting that arterial desaturation is likely to be an important limiting factor during submaximal exercise, and that supplemental $\mathrm{O}_{2}$ is a potential therapy for improving submaximal exercise capacity in patients with moderate-to-severe $\mathrm{CF}$. It was found that the benefits of supplemental $\mathrm{O}_{2}$ were greatest in patients who desaturated the most during a submaximal exercise test on room air. Three subjects showed no benefit with supplemental $\mathrm{O}_{2}$ (fig. 1). All three patients had evidence of severe airflow obstruction (FEV1 range $20-41 \%$ pred); however, none of the patients desaturated below $86 \%$ during the control study, while four of the five that improved exercise capacity with supplemental $\mathrm{O}_{2}$ desaturated below $86 \%$. There were no differences in body mass index, FEV1, FVC and resting $\mathrm{Sa}_{\mathrm{a}} \mathrm{O}_{2}$ between the responders and nonresponders.

\section{Mechanisms of improvement in exercise duration}

The current study was not designed specifically to study these mechanisms but there are a number of ways in which supplemental $\mathrm{O}_{2}$ can improve exercise capacity in patients with lung disease. Firstly, by preventing the ventilatory stimulation seen with hypoxia, supplemental $\mathrm{O}_{2}$ may increase the time patients with ventilatory limitation take to reach their maximum ventilatory capacity, thereby increasing exercise duration. This may also result in a reduced subjective sensation of dyspnoea during exercise, which may lead to improved exercise capacity. Secondly, supplemental $\mathrm{O}_{2}$ may improve $\mathrm{O}_{2}$ delivery to the exercising muscles, resulting in increased muscle endurance.

The authors' findings suggest that changes in the ventilatory response during exercise as well as improved oxygen delivery to the exercising muscles are likely to have contributed to the improvement in submaximal exercise capacity. The patients in this study reached the same level of peak ventilation at end exercise in the control and supplemental $\mathrm{O}_{2}$ studies, with a trend towards lower $V^{\prime} \mathrm{E}$ at matched submaximal exercise times. Increasing patient numbers may have given greater insight into the mechanism of exercise improvement, although for this trend to have become statistically significant, 80 patients would have been required [33] (at $50 \%$ of control duration: $\Delta V^{\prime} \mathrm{E}=5 \mathrm{~L} \cdot \mathrm{min}^{-1}, \mathrm{SD}=16.12$, power $\left.=0.8, \alpha=0.05\right)$. As the primary purpose of this study was to measure whether supplemental $\mathrm{O}_{2}$ improved submaximal exercise capacity, recruitment was limited to patient numbers that were sufficient to determine this.

The reason for an altered ventilatory response with supplemental $\mathrm{O}_{2}$ may be due to preventing hypoxia or by delaying onset of the anaerobic threshold. At end exercise, the patients in this study reached a peak $V^{\prime} \mathrm{E}>100 \%$ of pred MVV, suggesting that the patients may have been limited by ventilatory factors during exercise. This reduction in $V^{\prime} \mathrm{E}$, seen with supplemental $\mathrm{O}_{2}$, may have contributed to the improved exercise tolerance by increasing the time taken for the patients to reach their maximal ventilatory capacity. This has been described previously in patients with COPD $[34,35]$ and interstitial lung disease [36, 37]. Further work is necessary to determine whether the ventilatory response to hyperoxia is a factor in the improvement in submaximal exercise capacity seen in the $\mathrm{CF}$ patients in this study.

It is also likely that improved submaximal exercise capacity was as a result of improved $\mathrm{O}_{2}$ delivery to the exercising muscles. This could have been as a result of increasing the concentration of $\mathrm{O}_{2}$ in the blood and/or through improving cardiac output during exercise. An improvement in cardiac output may occur either by preventing hypoxic inhibition of myocardial contractility or preventing right ventricular dysfunction by reducing hypoxic pulmonary vasoconstriction. These factors have been shown to contribute to the benefits of $\mathrm{O}_{2}$ therapy during exercise in patients with COPD [38]. Increasing $\mathrm{O}_{2}$ delivery to the exercising muscles has been shown to result in delayed onset of lactic acidosis [39]. This reduction in metabolic acidosis facilitates glycolysis, which may improve the endurance capacity of the exercising muscle. The delay in onset of lactic acidosis may also decrease ventilatory demands during exercise, thereby increasing exercise capacity. Unfortunately, lactate levels were not measured in the patients in this study so it is unclear whether this played an important role.

In addition to both these mechanisms, altering the sensation of dyspnoea may have contributed to increased exercise duration. At end exercise, the subjects in this study had the same sensation of dyspnoea despite exercising for longer with supplemental $\mathrm{O}_{2}$. This delay in onset of dyspnoea could be a result of the delay in reaching peak $V^{\prime} \mathrm{E}$ or as a direct effect of preventing dyspnoea associated with hypoxaemia $[40,41]$. Further work is needed to clarify the role of dyspnoea in limiting submaximal exercise capacity in patients with $\mathrm{CF}$.

In conclusion, in patients with moderate-to-severe cystic fibrosis, submaximal exercise performance is likely to be limited in part by arterial hypoxaemia, and supplemental oxygen significantly improves submaximal exercise capacity. The mechanism resulting in improved submaximal exercise capacity is unclear and may relate to alteration in the ventilatory response during exercise, improved oxygen delivery to the exercising muscles or changes in the subjective sensation of dyspnoea. These mechanisms require further study. When designing an exercise programme for patients with moderate-to-severe cystic fibrosis, supplemental oxygen should be considered as a therapeutic option 
in patients who are unable to participate due to reduced submaximal exercise capacity associated with arterial desaturation.

\section{References}

1. Celli B. Exercise in the rehabilitation of patients with respiratory disease, pulmonary rehabilitation: guidelines to success. Philadelphia, Lippincott Williams \& Wilkins, 2000.

2. Pulmonary rehabilitation: joint ACCP/AACVPR evidence-based guidelines. ACCP/AACVPR Pulmonary Rehabilitation Guidelines Panel. American College of Chest Physicians. American Association of Cardiovascular and Pulmonary Rehabilitation. Chest 1997; 112: 1363-1396.

3. Pulmonary rehabilitation-1999. American Thoracic Society. Am J Respir Crit Care Med 1999; 159: 1666-1682.

4. Godfrey S, Mearns M. Pulmonary function and response to exercise in cystic fibrosis. Arch Dis Child 1971; 46: 144-151.

5. Coates AL, Boyce P, Muller D, Mearns M, Godfrey S. The role of nutritional status, airway obstruction, hypoxia, and abnormalities in serum lipid composition in limiting exercise tolerance in children with cystic fibrosis. Acta Paediatr Scand 1980; 69: 353-358.

6. Cerny FJ, Pullano TP, Cropp GJ. Cardiorespiratory adaptations to exercise in cystic fibrosis. Am Rev Respir Dis 1982; 126: 217-220.

7. Cropp GJ, Pullano TP, Cerny FJ, Nathanson IT. Exercise tolerance and cardiorespiratory adjustments at peak work capacity in cystic fibrosis. Am Rev Respir Dis 1982; 126: 211-216.

8. Marcotte JE, Grisdale RK, Levison H, Coates AL, Canny GJ. Multiple factors limit exercise capacity in cystic fibrosis. Pediatr Pulmonol 1986; 2: 274-281.

9. Nixon PA, Orenstein DM, Kelsey SF, Doershuk CF. The prognostic value of exercise testing in patients with cystic fibrosis. N Engl J Med 1992; 327: 17851788 .

10. Moorcroft AJ, Dodd ME, Webb AK. Exercise testing and prognosis in adult cystic fibrosis. Thorax 1997; 52: 291-293.

11. de Jong W, Kaptein AA, van der Schans CP, et al. Quality of life in patients with cystic fibrosis. Pediatr Pulmonol 1997; 23: 95-100.

12. Orenstein DM, Nixon PA, Ross EA, Kaplan RM. The quality of well-being in cystic fibrosis. Chest 1989; 95: 344-347.

13. Nixon PA. Role of exercise in the evaluation and management of pulmonary disease in children and youth. Med Sci Sports Exerc 1996; 28: 414 420.

14. Stanghelle JK. Physical exercise for patients with cystic fibrosis: a review. Int J Sports Med 1988; 9: Suppl. 1, 6-18.

15. Casaburi R, Patessio A, Ioli F, Zanaboni S, Donner $\mathrm{CF}$, Wasserman $\mathrm{K}$. Reductions in exercise lactic acidosis and ventilation as a result of exercise training in patients with obstructive lung disease. Am Rev Respir Dis 1991; 143: 9-18.

16. Casaburi R, Porszasz J, Burns MR, Carithers ER, Chang RS, Cooper CB. Physiologic benefits of exercise training in rehabilitation of patients with severe chronic obstructive pulmonary disease. Am J Respir Crit Care Med 1997; 155: 1541-1551.
17. Marcotte JE, Canny GJ, Grisdale R, et al. Effects of nutritional status on exercise performance in advanced cystic fibrosis. Chest 1986; 90: 375-379.

18. Coates AL, Boyce P, Muller D, Mearns M, Godfrey S. The role of nutritional status, airway obstruction, hypoxia and abnormalities in serum lipid composition in limiting exercise tolerance in children with cystic fibrosis. Bull Eur Physiopathol Respir 1979; 15: 341-342.

19. Lands LC, Heigenhauser GJ, Jones NL. Analysis of factors limiting maximal exercise performance in cystic fibrosis. Clin Sci (Colch) 1992; 83: 391-397.

20. Lands LC, Heigenhauser GJF, Jones NL. Respiratory and peripheral muscle function in cystic fibrosis. $\mathrm{Am}$ Rev Respir Dis 1993; 147: 865-869.

21. Marcus CL, Bader D, Stabile MW, Wang CI, Osher $\mathrm{AB}$, Keens TG. Supplemental oxygen and exercise performance in patients with cystic fibrosis with severe pulmonary disease. Chest 1992; 101: 52-57.

22. Nixon PA, Orenstein DM, Curtis SE, Ross EA. Oxygen supplementation during exercise in cystic fibrosis. Am Rev Respir Dis 1990; 142: 807-811.

23. Heijerman HG, Bakker W, Sterk PJ, Dijkman JH. Oxygen-assisted exercise training in adult cystic fibrosis patients with pulmonary limitation to exercise. Int J Rehabil Res 1991; 14: 101-115.

24. Heijerman HG, Bakker W, Sterk PJ, Dijkman JH. Long-term effects of exercise training and hyperalimentation in adult cystic fibrosis patients with severe pulmonary dysfunction. Int $J$ Rehabil Res 1992; 15: 252-257.

25. Lung volumes and forced ventilatory flows. Report: Working party standardisation of lung function tests, European community for steel and coal. Eur Respir $J$ 1993; 6: S16.

26. Welch H, Pedersen PK. Measurement of metabolic rate in hyperoxia. J Appl Physiol 1981; 51: 725-731.

27. Jones NL. Clinical exercise testing. 3rd Edn Philadelphia, Saunders, 1988.

28. Wasserman K, Hanson JE, Sue DY, Casaburi R, Whipp BJ. Principles of exercise testing and interpretation. 3rd Edn. Philadelphia, Lea and Febiger, 1999.

29. Clarke TJ, Freedman S, Campbell EJ. The ventilatory capacity of patients with chronic airways obstruction. Clin Sci 1969; 36: 307-316.

30. Borg G. Psychophysical basis of perceived exertion. Med Sci Sports Exerc 1982; 14: 377-381.

31. Daly LE, Bourke GJ, McGilvray J. Interpretation and uses of medical statistics. 4th Edn. London, Blackwell Science, 1991.

32. Welsh H. Hyperoxia and human performance: a brief review. Med Sci Sports Exer 1982; 14: 254-262.

33. Glantz SA. Primer of bio-statistics. 3rd Edn. New York, McGraw-Hill, 1992.

34. Dean NC, Brown JK, Himelman RB, Doherty JJ, Gold WM, Stulbarg MS. Oxygen may improve dyspnea and endurance in patients with chronic obstructive pulmonary disease and only mild hypoxemia. Am Rev Respir Dis 1992; 146: 941-945.

35. Light RW, Mahutte CK, Stansbury DW, Fischer CE, Brown SE. Relationship between improvement in exercise performance with supplemental oxygen and hypoxic ventilatory drive in patients with chronic airflow obstruction. Chest 1989; 95: 751-756.

36. Harris-Eze AO, Sridhar G, Clemens RE, Gallagher CG, Marciniuk DD. Oxygen improves maximal 
exercise performance in interstitial lung disease. $\mathrm{Am}$ J Respir Crit Care Med 1994; 150: 1616-1622.

37. Harris-Eze A, Sridar G, Clemens R, Zintel T, Gallagher C, Marciniuk D. Role of hypoxaemia and pulmonary mechanics in exercise limitation in interstitial lung disease. Am J Respir Crit Care Med 1996; 154: 994-1001.

38. Corriveau ML, Rosen BJ, Dolan GF. Oxygen transport and oxygen consumption during supplemental oxygen administration in patients with chronic obstructive pulmonary disease. Am J Med 1989; 87: 633-637.
39. Linossier MT, Dormois D, Arsac L, et al. Effect of hyperoxia on aerobic and anaerobic performances and muscle metabolism during maximal cycling exercise. Acta Physiol Scand 2000; 168: 403-411.

40. Davidson A, Leach R, George R, Geddes D. Supplemental oxygen and exercise ability in chronic obstructive airways disease. Thorax 1988; 43: 965971.

41. Woodcock AA, Gross ER, Geddes DM. Oxygen relieves breathlessness in "pink puffers". Lancet 1981; 1: 907-909. 